\title{
The Photocatalytic Degradation of Phenanthrene using Graphene oxide bismuth molybdate
}

\author{
E. Fosso-Kankeu, G. Benade, S. Maswanganyi, N. Kumar, R. Gusain, F. Waanders, S. Pandey and S. S. \\ Ray
}

\begin{abstract}
Polycyclic Aromatic Hydrocarbons (PAHs) are very difficult to remove from water sources by means of conventional methods and thus require a new and improved technique. One of the options, that is investigated in this study, is the use of the photocatalyst, graphene oxide bismuth molybdate. The purpose of the photocatalyst is to break down the PAHs in the presence of visible light.

The use of this specific photocatalyst has already been proven to be effective in the removal of PAHs. The hydrothermal method had been chosen in this study as the most effective method to use due to the low temperatures (higher than $100^{\circ} \mathrm{C}$ ) required, higher purity of the products obtained, more control over the structure formed, etc.

There are, however, certain aspects concerning the hydrothermal method, that have an effect on the structure and, thus, the efficiency of the photocatalyst. These aspects include the $\mathrm{pH}$ and temperature at which the photocatalyst is synthesized. These aspects were investigated in this study.

The results showed the most effective photocatalyst synthesized at $150^{\circ} \mathrm{C}$ and at a $\mathrm{pH}$ of 9 , was able to degrade $50 \%$ of phenanthrene after $125 \mathrm{~min}$. It is therefore imperative to synthesize the photocatalyst under optimum conditions to obtain the desired properties and performance.
\end{abstract}

Keywords - graphene oxide bismuth molybdate, hydrothermal method, $\mathrm{pH}$, Phenanthrene, photocatalytic degradation, temperature

\section{INTRODUCTION}

Coal-tar is a product that is formed during coal processing, such as coal coking or coal gasification. During these processes a liquid waste product forms that contains coal-tar. This liquid is very difficult to treat and usually ends up in heaps and landfills. Due to this disposal method, the coal-tar can easily leach into the ground and into the groundwater sources [1].

Manuscript received October, 2020.

E Fosso-Kankeu, G. Benade, S. Maswanganyi, and F Waanders are with the Water Pollution Monitoring and Remediation Initiatives Research Group, School of Chemical and Minerals Engineering, North-West University, Potchefstroom, South Africa.

N Kumar and SS Ray are with DST/CSIR National Centre for Nanostructured Materials, Council for Scientific and Industrial Research, Pretoria 0001, South Africa.

R Gusain and SS Ray are with the Department of Applied Chemistry, University of Johannesburg, Doornfontein 2028, Johannesburg, South Africa

S. Pandey is with the Water Pollution Monitoring and Remediation Initiatives Research Group, School of Chemical and Minerals Engineering, North-West University, Potchefstroom, South Africa
Coal-tar contains molecules called polycyclic aromatic hydrocarbons (PAHs). These molecules are carcinogenic to humans and are considered to be very harmful to humans and also other forms of life [2]. It is thus very important that these PAHs be removed from water sources.

A possible solution to do this, is to make use of the photocatalyst, graphene oxide bismuth molybdate. A photocatalyst is a substance that absorbs light and then releases electrons to its surface to form electron-hole pairs. The change in charge at the surface of the photocatalysts then produces free radicals. These free radicals then break down organic pollutants, such as PAHs, present in the water [3].

Photocatalysts are usually semiconductor materials. Semiconductors are materials that require a small amount of energy to release electrons from the valence band to the conduction band. The amount of energy required to release these electrons, is called the band gap. The lower the band gap, the less energy is required to excite the electrons [4].

Graphene oxide is a carbon rich substance that is deposited on the surface of the photocatalyst. Graphene oxide increases the absorptivity of the photocatalyst and prevents the recombination of the electron-hole pairs. Graphene oxide can be used to control the structure of the photocatalyst, that will in turn increase the effectiveness thereof [5]. The quantity of graphene oxide that is used during the synthesis of the photocatalyst is an important factor to take into account [6]. Graphene oxide was then coupled with $\mathrm{Bi}_{2} \mathrm{MoO}_{6}$ in order to reduce the ban gap and delay the recombination of the electron-hole pairs.

There are different bismuth molybdate structures that can form during synthesis, namely $\mathrm{Bi}_{2} \mathrm{MoO}_{6}, \mathrm{Bi}_{2} \mathrm{Mo}_{3} \mathrm{O}_{12}$ and $\mathrm{Bi}_{2} \mathrm{Mo}_{2} \mathrm{O}_{9}$. The structure, according to literature, that has the lowest band gap and highest absorption of light, is the structure $\mathrm{Bi}_{2} \mathrm{MoO}_{6}$. This would make this structure the best and most efficient photocatalyst. However, there are certain factors that can affect the structure formed during synthesis. These factors include the Bi:Mo ratio, synthesis $\mathrm{pH}$ and temperature [7]. In this study, the effect of the synthesis conditions $(\mathrm{pH}$ and temperature) during hydrothermal synthesis of the photocatalyst, graphene oxide bismuth molybdate, is investigated. 


\section{METHODOLOGY}

\section{A. Materials}

The chemicals used in this experiment included sodium molybdate, bismuth nitrate pentahydrate $98 \%$, phenanthrene

$98 \%$, graphene oxide flakes (15-20 sheets), nitric acid $2 \mathrm{M}$ solution, ammonia $25 \%$ solution, methanol and deionized water which were purchased from Sigma Aldrich South Africa.

\section{B. Preparation of Graphene Oxide solution}

$1 \mathrm{~g}$ of graphene oxide powder were added to 1 liter of deionized water to form a $1000 \mathrm{mg} / \mathrm{l}$ solution. The solution was sonicated for 60 minutes at a frequency of $35 \mathrm{kHz}$ to ensure dissolution of all graphene oxide [8].

\section{Hydrothermal Synthesis of Graphene Oxide Bismuth Molybdate}

$5 \mathrm{mmol}$ bismuth nitrate pentahydrate was dissolved in $10 \mathrm{~mL}$ of nitric acid. As the molar Bi:Mo ratio was chosen as 2:1, 2.5 mmol sodium molybdate was dissolved in $10 \mathrm{~mL}$ of deionized water. $30 \mathrm{~mL}$ of graphene oxide solution was added to the sodium molybdate solution. The bismuth nitrate solution was added to the sodium molybdate solution and stirred vigorously for 15 minutes. Thereafter, the $\mathrm{pH}$ was adjusted to the desired $\mathrm{pH}$ using ammonia $25 \%$ solution [9]. A pH of 4, 7 and 9 were investigated during this experiment.

The solution was placed in an autoclave for 16 hours at the desired temperature. Temperatures of $120^{\circ}, 150^{\circ} \mathrm{C}$ and $180^{\circ} \mathrm{C}$ were investigated. The product was removed from the autoclave and filtered. The filtrate was washed multiple times using deionized water [9].

\section{Characterization of Photocatalysts}

The synthesized photocatalysts were characterized using $\mathrm{X}$-ray powder diffraction (XRD), Fourier-transform infrared spectroscopy (FTIR) and Scanning Electron Microscopy with Energy Dispersive Spectroscopy (SEM-EDS).

\section{E. Photocatalytic Degradation of Phenanthrene}

Based on the characterization of the photocatalysts produced, three catalysts were chosen from each synthesis temperature.

$25 \mathrm{mg}$ of Phenanthrene were dissolved in $30 \mathrm{~mL}$ methanol. 70 $\mathrm{mL}$ deionized water were added to form a $0.25 \mathrm{mg} / \mathrm{mL}$ solution. Six samples were prepared. $30 \mathrm{mg}$ of each photocatalyst were added to a phenanthrene sample. The samples were placed in the dark for 20 minutes where after $5 \mathrm{~mL}$ were taken from the samples to determine the amount of phenanthrene present in the sample. Afterwards, the samples were placed in a light source (The $300 \mathrm{~W}$ Xe lamp with a UV cut-off glass filter $(\lambda>420 \mathrm{~nm})$ was used for sample irradiation [8]) and $5 \mathrm{~mL}$ samples were taken and tested every 25, 50, 75, 100 and 125 minutes. The amount of phenanthrene present in the samples was determined by using UV visual spectroscopy. The absorption of Phenanthrene was determined at the wavelength of 271 nm [10].

\section{RESULTS AND DISCUSSION}

\section{A. Characterization Results}

The absorbance of the synthesized catalysts was analyzed by doing an FTIR analysis, using Shimadzu IRAffinity equipment. These results can be seen in Fig. 1. The percentage of transmittance of light were detected over different wavelengths.

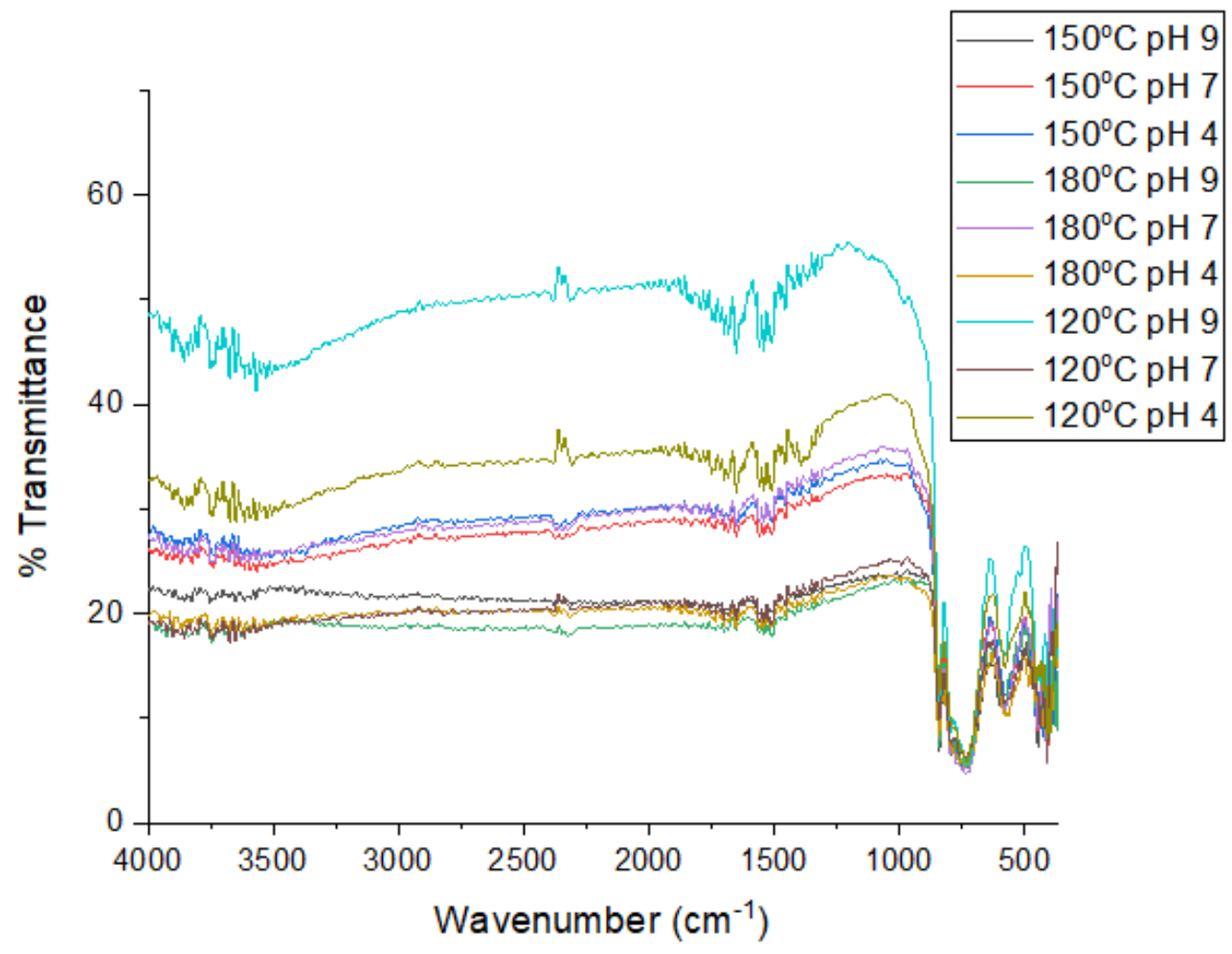

Fig. 1: FTIR results of all synthesized photocatalysts 

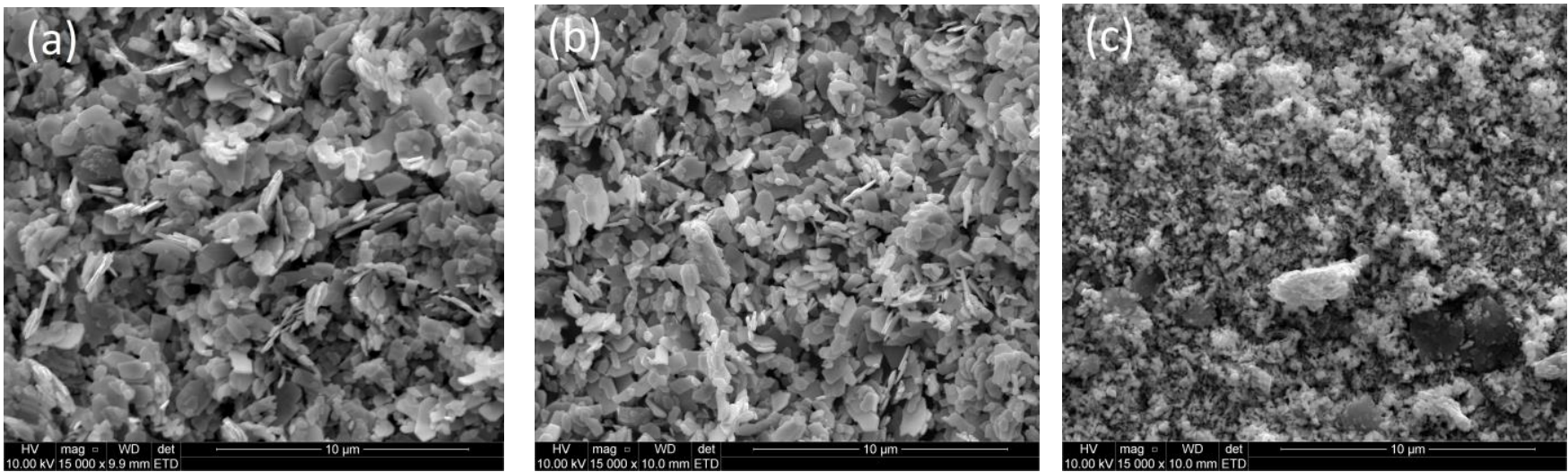

Fig. 2: SEM results of the three chosen photocatalysts synthesized at (a) $150^{\circ} \mathrm{C}$ and $\mathrm{pH}$ of 9 , (b) $180^{\circ} \mathrm{C}$ and $\mathrm{pH}$ of 9 and (c) $120^{\circ} \mathrm{C}$ and $\mathrm{pH}$ of 7

Based on the FTIR results, a photocatalyst from each synthesis temperature, with the highest indicated absorbance, was chosen to test the phenanthrene degradation efficiency of each. The photocatalysts chosen included the catalysts synthesized at $150^{\circ} \mathrm{C}$ with a $\mathrm{pH}$ of $9,180^{\circ} \mathrm{C}$ with a $\mathrm{pH}$ of 9 and $120^{\circ} \mathrm{C}$ with a pH of 7 .

According to literature, bismuth molybdate with the structure $\mathrm{Bi}_{2} \mathrm{MoO}_{6}$ has the lowest band gap and the highest absorbance of all the structures [7]. The band gap refers to the amount of energy that is required for electrons to be released to the surface of the photocatalyst; or in other word, to move from the valence band to the conduction band [4]. That is why this specific structure is desired. This structure is believed to form at higher $\mathrm{pH}$ values, such as 7 and 9. The other structure of bismuth molybdate is $\mathrm{Bi}_{2} \mathrm{Mo}_{3} \mathrm{O}_{12}$. This structure can also function as a photocatalyst, but it has a lower band gap and a lower absorbance than the previously mentioned structure. It is believed that this specific structure forms at lower $\mathrm{pH}$ values, such as 4 [7]. This literature is also supported by [9]. This phenomenon can be observed in the FTIR results, as the three photocatalysts with the highest absorbance were all synthesized at $\mathrm{pH}$ values 7 and 9 .

A SEM-EDS analysis was done to determine the morphology of the photocatalysts, as well as to determine the visual elements present in the structure. The SEM photographs of the three chosen catalysts can be seen in Fig. 2. From these results, a definite change in structure can be seen in the photocatalyst synthesized at $120^{\circ} \mathrm{C}$. The photocatalysts synthesized at temperatures of $150^{\circ} \mathrm{C}$ and $180^{\circ} \mathrm{C}$ seems to have more or less the same solid crystalline structure.

The SEM-EDS results of the chosen catalysts can be seen in Table 1.

TABLE I: SEM-EDS RESULTS OF 3 CHOSEN PHOTOCATALYSTS

\begin{tabular}{llll}
\hline \hline & Carbon $(\%)$ & Bismuth $(\%)$ & Molybdenum $(\%)$ \\
\hline $150^{\circ} \mathrm{C} \mathrm{pH} 9$ & 47.16 & 29.01 & 5.66 \\
$180^{\circ} \mathrm{C} \mathrm{pH} 9$ & 26.51 & 47.19 & 9.76 \\
$120^{\circ} \mathrm{C} \mathrm{pH} \mathrm{7}$ & 21.3 & 50.97 & 10.82 \\
\hline \hline
\end{tabular}

From Table 1, one can see that the Bi: Mo ratio stayed constant during synthesis and showed a similar mole ratio, as specified in the methodology. However, the photocatalyst synthesized at a temperature of $150^{\circ} \mathrm{C}$, has a larger amount of graphene oxide deposited on its surface. The photocatalyst developed at a temperature of $120^{\circ} \mathrm{C}$ shows a much smaller amount of graphene oxide available of its surface. The amount of graphene oxide available on the surface of the catalysts is also determining factor, as a large amount of graphene oxide can have many advantages such as the prevention of the recombination of electron-hole pairs. However, too much graphene oxide can have a negative effect on the efficiency of a photocatalyst. If the graphene oxide deposited on the surface of the catalyst is too much, then the light cannot reach the surface of the photocatalyst.

\section{A. Photocatalytic Degradation of Phenanthrene Results}

The photocatalytic degradation test was done in a photocatalytic chamber, using visible light. The remaining concentration of Phenanthrene was determined by measuring the absorbance of the solution using a Genesys UV-Vis Spectrophotometer.

The trend of how concentration changed over time, using the photocatalysts chosen, can be seen in Fig. 3.

The photocatalyst synthesized at temperature $120^{\circ}$ shows some fluctuation of the concentration, however, no Phenanthrene degradation had taken place. The photocatalyst has proven to be inefficient and defective. Taken into account how the other two catalysts synthesized at $120^{\circ} \mathrm{C}$ shows low absorbance in Figure 1, it can be concluded that the synthesis temperature is ineffective. With regards to the large difference in structure of the photocatalyst synthesized at $120^{\circ} \mathrm{C}$, that can be seen in Figure 2, it is also possible to conclude that the reaction to form the desired structure of bismuth molybdate was not completed, or another structure had formed altogether.

The other two catalysts synthesized at temperatures of $150^{\circ} \mathrm{C}$ and $180^{\circ} \mathrm{C}$ shows to be more efficient. From the graph in Fig. 3, the concentration of Phenanthrene was shown to decrease as time increased.

The photocatalyst synthesized at a temperature of $150^{\circ} \mathrm{C}$ and a pH of 9 , shows poor degradation in the first few minutes. The photocatalyst was left in the dark for the first 20 minutes of the experiment, so this can explain why photocatalytic degradation is slow, initially. However, the photocatalytic degradation rapidly increases to degrade up to 53\% of Phenanthrene in 125 minutes exposed to light. 


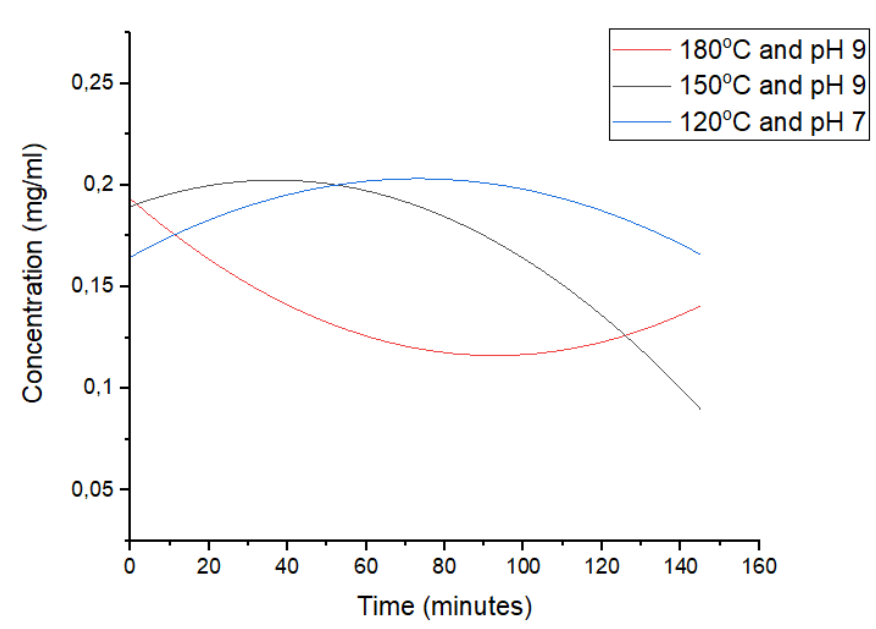

Fig. 3: Change in Phenanthrene concentration over time

The catalyst synthesized at $180^{\circ} \mathrm{C}$ shows acceptable phenanthrene degradation efficiency of up to about $27 \%$. However, it has only $26.51 \%$ carbon available on its surface, which can render it less effective than the photocatalyst synthesized at temperature of $150^{\circ} \mathrm{C}$.

The photocatalyst synthesized at $180^{\circ} \mathrm{C}$ shows an immediate decrease in the phenanthrene concentration. It is possible that during the time that the photocatalyst was added to the sample, it might have been exposed to light, that caused photocatalytic degradation to take place during the dark period. Another reason might be due to the adsorption of phenanthrene onto the photocatalyst. Graphene oxide enhances adsorption of aromatic pollutants which will facilitate photocatalytic degradation. However, when a sample is filtered in order to get the photocatalyst out of the samples before analysis, some of the phenanthrene, that adsorbed to the surface of the catalyst, can be filtered out as well [6]. This phenomenon can also explain why an increase in concentration of phenanthrene is observed after 145 minutes.

Both the catalysts (synthesized at temperature $150^{\circ} \mathrm{C}$ and $180^{\circ} \mathrm{C}$ ) were synthesized at a $\mathrm{pH}$ value of 9 . This supports the literature indicating that the desired structure of bismuth molybdate $\mathrm{Bi}_{2} \quad \mathrm{MoO}_{6}$ is synthesized at higher $\mathrm{pH}$ values [7].

\section{CONCLUSION}

It can be concluded that the optimal conditions to synthesize Graphene Oxide Bismuth Molybdate is a synthesis temperature and $\mathrm{pH}$ value of $150^{\circ} \mathrm{C}$ and 9 , respectively. This photocatalyst degraded about $50 \%$ of the Phenanthrene in 125 minutes.

From literature, it was determined that the desired form of Bismuth Molybdate will form at higher $\mathrm{pH}$ values, like 7 and 9. This would explain why a $\mathrm{pH}$ value of 9 is optimal for the synthesis procedure. At lower $\mathrm{pH}$ values, such as 4 , another form of bismuth molybdate, $\mathrm{Bi}_{2} \mathrm{Mo}_{3} \mathrm{O}_{12}$, will form.

It is therefore obvious that both the temperature and $\mathrm{pH}$ played a crucial role in the synthesis of the suitable photocatalyst. A wide range of temperature and $\mathrm{pH}$ should be considered in future to identify improved synthesis conditions to produce a most effective photocatalyst.

\section{ACKNOWLEDGMENT}

The authors are thankful to the sponsors: the Water Research Commission (WRC, Project 2974) and the North-West University in South Africa.

\section{REFERENCES}

[1]E. Fosso-Kankeu, "Coal Tar Production Processes and Potential of PAHs Release into the Environment," pp. 246-250, 2019.

[2]N. National Cancer Institute, "Coal-Tar and Coal-Tar Pitch," 2018. [Online]. Available: https://www.cancer.gov/about-cancer/causes-prevention/risk/substances /coal-tar. [Accessed 9 February 2020].

[3]T. Leshuk, "Photocatalytic Water Treatment," 2015.

[4]P. Desario and K. Gray, "Photocatalytic materials," Passive systems to improve air quality and reduce heat retention in the urban environment, 2012.

https://doi.org/10.1533/9780857096463.3.292

[5]J. Zou, J. Ma, Q. Huang, S. Luo, J. Yu and X. Luo, "Graphene oxide as structure-directing and morphology-controlling agent for the syntheses of heterostructured photocatalytic activity," Applied Catalysis B, Environmental, Vols. 156-157, pp. 447-455, 2014. https://doi.org/10.1016/j.apcatb.2014.03.038

[6]D. Yoo, T. Cuong, V. Pham, J. Chung, N. Khoa, E. Kim and S. Hahn, "Enhanced photocatalytic activity of graphene oxide decorated on $\mathrm{TiO}_{2}$ films under UV and visible irradiation," Current Applied Physics, vol. 11, no. 3, pp. 805-808, 2011. https://doi.org/10.1016/j.cap.2010.11.077

[7]H. Li, K. Li and H. Wang, "Hydrothermal synthesis and photocatalytic properties of bismuth molybdate materials," Materials Chemistry and Physics, vol. 116, no. 1, pp. 134-142, 2009. https://doi.org/10.1016/j.matchemphys.2009.02.058

[8]N. Mukwevho, R. Gusain, E. Fosso-Kankeu, N. Kumar, F. Waanders and S. Ray, "Removal of naphthalene from simulated wastewater through adsorption-photodegradation by $\mathrm{ZnO} / \mathrm{Ag} / \mathrm{GO}$ nanocomposite," Journal of Industrial and Engineering Chemistry, vol. 81, pp. 393-404, 2020. https://doi.org/10.1016/j.jiec.2019.09.030

[9]K. Schuh, W. Kleist, M. Hoj, V. Trouillet, P. Beato, A. Jenson and J. Grunwaldt, "Bismuth Molybdate Catalysts Prepared by Mild Hydrothermal Synthesis: Influence of $\mathrm{pH}$ on the Selective Oxidation of Propylene," pp. 1554-1573, 2015. https://doi.org/10.3390/catal5031554

[10] N. Mukwevho, E. Fosso-Kankeu, F. Waanders, N. Kumar, S. Ray and X. Yangkou Mbianda, "Photocatalytic activity of $\mathrm{Gd}_{2} \mathrm{O}_{2} \mathrm{CO}_{3} \cdot \mathrm{ZnO} \cdot \mathrm{CuO}$ nanocomposite used for the degradation of phenanthrene," SN Applied Sciences, vol. 1, no. 1, 2019.

https://doi.org/10.1007/s42452-018-0012-0 